DOI: $10.33467 /$ coemci 13687

\title{
Práticas educativas e curriculares desenvolvidas no Curso de graduação em Biblioteconomia
}
Educational and curricular practices developed in the undergraduate course in Librarianship
Prácticas educativas y curriculares desarrolladas en el Curso de Biblioteconomía

\section{Raimunda Ramos MARINHO ${ }^{1}$}

\section{Correspondência}

Autor para correspondência. Raimunda Ramos Marinho

Endereço completo: Alameda dos Sonhos, n50 Residencial Turmalina- 65060-280 -São Luís - MA

E-mail: rr.marinho@ufma.br

ORCID: https://orcid.org/0000-0002-6034-

$\underline{3449}$

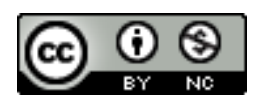

Submetido em: 01/12/2019

Aceito em: 02/01/2020

Publicado em: 22/05/2020

1 Mestre em Ciência da Informação pela Pontifícia Universidade Católica de Campinas. Doutoranda pelo Programa de Pós-Graduação em Educação da Universidade Federal do Maranhão (UFMA) e Professora Assistente do Departamento de Biblioteconomia - UFMA. 


\section{RESUMO}

Análise das necessidades formativas e do perfil profissional, elementos que são entendidos como produto das relações sociais mediadas pelas atividades humanas, mas que, ao longo do processo de formação profissional, sofrem significativas mudanças, pois tornam-se reflexo das transformações ocorridas no contexto em que estão inseridos. O objetivo deste ensaio é trazer a lume a preocupação com determinadas expectativas formativas do processo de profissionalização do bibliotecário e do mundo do trabalho informacional, de modo a destacar as competências de gestão necessárias ao exercício profissional em contextos de relações sistêmicas, complexas e incertas. As reflexões se pautam em aspectos teóricos sobre práticas docentes e na experiência desenvolvida no curso de graduação em Biblioteconomia da Universidade Federal do Maranhão (UFMA).Toma-se como ponto de referência o componente curricular 'Planejamento em unidades de informação'.É um relato de experiência de natureza qualitativa, caráter descritivo e que objetiva registrar uma situação real,baseada no trabalho cotidiano ou nas experiências de sala de aula,bem comoelencar os princípios que fundamentam as práticas pedagógicas.De acordo com a perspectiva teórica adotada, essas situações só podem ser compreendidas na perspectiva da totalidade, ou seja, como síntese de múltiplas contradições.Conclui-se que a formação profissional de bibliotecáriosnos cursos de graduação possui fragilidades empíricas, sendo que as principais são: fragmentação do ensino entre conteúdos,repasse do conhecimento prático-conceitual e ausência de adequada visão geral e sistêmica de organização/empresa.

Palavras-chave: Biblioteconomia-Currículo. Necessidades formativas. Planejamento em unidades de informação.

\section{ABSTRACT}

Analysis of training needs and professional profile, elements that are understood as a product of social relations mediated by human activities, but which, throughout the process of professional training, undergo significant changes as a reflection of the changes that occurred in the context in which they are inserted. The aim of this essay will be to highlight the concern with certain formative expectations of the librarian's professionalization process and the world of informational work, in order to highlight the management skills necessary for professional librarian practice in contexts of systemic, complex, uncertainties. The reflections are based on theoretical aspects about teaching practices, and on the experience developed in the Undergraduate Course in Librarianship at the Federal University of Maranhão (UFMA), taking as a reference point the curricular component 'Planning in information units'. Experience report of a qualitative nature, descriptive character that. It aims to record a real situation based on daily work, or classroom experiences to list the principles that underpin pedagogical practices, which, according to the 
theoretical perspective adopted, can only be understood from the perspective of totality, that is, as a synthesis multiple contradictions. It concludes with a contribution to the process of critical reflection about the professional training of librarians in undergraduate courses, based on one of its main empirical weaknesses observed: the fragmentation of teaching between content, and the transfer of practical-conceptual knowledge, and the resulting absence of an adequate general and systemic overview of the organization / company.

Keywords: Educational practice. Librarianship-Curriculum. Planning in information units. Training needs.

\section{RESUMEN}

Análisis de las necesidades de capacitación y perfil profesional, elementos que se entienden como producto de las relaciones sociales mediadas por actividades humanas, pero que, a lo largo del proceso de capacitación profesional, experimentan cambios significativos, ya que se convierten en un reflejo de los cambios que ocurrieron en el contexto en el que están insertados El propósito de este ensayo es resaltar la preocupación con ciertas expectativas formativas del proceso de profesionalización del bibliotecario y el mundo del trabajo informativo, con el fin de resaltar las habilidades de gestión necesarias para la práctica profesional en contextos de relaciones sistémicas, complejas e inciertas. Las reflexiones se basan en aspectos teóricos sobre las prácticas docentes y la experiencia desarrollada en el curso de licenciatura en Biblioteconomía de la Universidad Federal de Maranhão (UFMA). El componente curricular 'Planificación en unidades de información' se toma como punto de referencia. naturaleza cualitativa, carácter descriptivo y cuyo objetivo es registrar una situación real, basada en el trabajo diario o experiencias en el aula, así como enumerar los principios que sustentan las prácticas pedagógicas. Según la perspectiva teórica adoptada, estas situaciones solo pueden entenderse en la perspectiva de la totalidad, es decir, como una síntesis de múltiples contradicciones Se concluye que la formación profesional de los bibliotecarios en los cursos de pregrado tiene debilidades empíricas, siendo las principales: fragmentación de la enseñanza entre contenidos, transferencia de conocimiento prácticoconceptual y ausencia de una visión general adecuada de organización / empresa.

Palabras clave: Biblioteconomía-Currículum. Necesidades formativas. Planificación en unidades de información

\section{INTRODUÇÃO}

O processo de formação profissional é norteado pelo grau de desenvolvimento das sociedades. A Ciência e a Tecnologia, 
em escala crescente, tiveram papel fundamental no aumento da produção de bens materiais. Outrossim, foram impondo novos conceitos, hábitos e costumes, definindo novas formas de organização do trabalho, novos padrões de comportamento humano, exigindo novas relações de produção e de trabalho. Naquelas sociedades ditas de ideologia capitalista, é comum a (re) moldagem de conceitos relacionados ao mundo do trabalho.

Dessa perspectiva, são evidentes as características distintivas da Biblioteconomia no seu campo de atuação profissional, com uma conjunção de paradigmas que acenam para uma mutação, e da revolução informacional, como trata Lojkine (1995).

Nessa dinâmica, as forças produtivas nesse campo do conhecimento não são reduzidas aos instrumentos ou tecnologias, já que a reprodução social se apresenta a partir da sua inserção na divisão social e técnica do trabalho, trazendo à luz a necessidade de tornar mais explícito o que está implícito, ou o não aparente da totalidade das relações entre o homem e a maneira de produzir nas interações sociais.

Independentemente do enfoque atribuído a essas relações no campo biblioteconômico, ainda que seja na perspectiva racionalista, a sua totalidade não se encerra no seu próprio objeto. Por essa razão, o todo se concentra na infinitude do seu objeto.

O todo é maior que a soma das partes, por isso, cabe a reflexão acerca dos entes que o compõem, como estruturas, 
métodos e técnicas utilizadas no processo de formação dos saberes profissionais. Esses entes respondem pela formação do capital humano biblioteconômico, a qual se destina às atividades fundadas no tratamento da informação e oriundas do campo informacional.

Pode-se afirmar que a competência do profissional bibliotecário tem origem numa totalidade proveniente de diferentes saberes, os quais são construídos nos espaços acadêmico e social, vinculados por diferentes relações. Com efeito, torna indispensável para os sujeitos profissionais a compreensão e a capacidade de interpretar a constituição e as contradições do mundo bibliotecal, com vistas ao estabelecimento de sistemas de produção para geração de variados serviços e produtos de natureza informacional.

Reforçando esse raciocínio, Pochmann (2001, p. 89) afirma que"[...] desajuste entre a mão-de-obra demandada pelo processo de acumulação do capital e a mão-de-obra disponível no mercado de trabalho" implica mudanças nas formas de gerir e organizar os processos de produção na atual divisão internacional do trabalho.Dito de outra forma,há uma fluidez de funções e mobilidade de atividades, o que impõe, inclusive ao profissional bibliotecário, a necessidade do desenvolvimento de aptidões e de uma expertise informacional, a partir da incorporação de habilidades e conhecimentos para distinção profissional, de modo a absorver os novos postos de trabalho que estão por vir. 
Nessa direção, Levy (2016) observa a relação mensurável entre produtividade do trabalho, qualificação profissional e educação superior, deixando clara a existência de uma forte correlação.Ao relacionar essa lógica com a questão fator de produção,sem nenhuma sutileza do forte valor mercantil com a educação superior, nota-se que esse segmento se volta para os interesses de mercado com efeitos coercitivos,como é demonstrado por Martineli(2009, p.90):

O confronto entre as concepções de Universidade e de Educação Superior são históricas e, por isto, clássicas, e as concepções neoliberais, de cunho ideológico e economicista, tem provocado debates, discussões, críticas e movimentos de resistência no mundo, na América Latina e Caribe.

No mundo marcado pela mercantilização não só de bens, mas de serviços e produtos, a tese mercadológica ganha solidez no campo da educação brasileira, cujos discursos sobre investimentos são tidos como dispendiosos para o ensino superior, obrigando à formação de profissionais que estrategicamente possam responder à lógica capitalista com qualidade e produtividade.

Em resumo,a questão morfológica do mundo trabalho às vezes parece estar num movimento localizado, mas, ao contrário, está claro que também alcança veementemente o campo da Biblioteconomia, como é reforçado por Lojkine (1995, p.71): "A revolução informacional abriga potencialidades de ultrapassagem das divisões atuais entre trabalhadores produtivos e trabalhadores improdutivos de mais -valia, trabalhadores da produção material". 
Considerando o breve contexto apresentado, o objetivo deste ensaio é trazer a lume a preocupação com determinadas expectativas formativas do processo de profissionalização do bibliotecário e do mundo do trabalho informacional, de modo a destacar as competências de gestão necessárias ao exercício profissional em contextos de relações sistêmicas, complexas e incertas.As reflexões se pautam em aspectos teóricos sobre práticas docentes e na experiência desenvolvida no curso de graduação em Biblioteconomia da Universidade Federal do Maranhão (UFMA), tomando como ponto de referência o componente curricular 'Planejamento em unidades de informação'.

Neste estudo, tomou-se a valorosa abordagem desenvolvida por Tardif (2014) a respeito da problemática contemporânea dos fundamentos sobre saberes docentes e formação profissional. Além disso, foram incorporadas apreciações sobre o ensino de Biblioteconomia, cujo acervo ainda é reduzido a respeito do tema.

Sem tratar de modelos formais, urge pensar em um diálogo sobre saberes, conhecimentos e práticas docentes como adequado pressuposto teórico-prático indispensável ao compromisso institucional dos cursos de graduação. Inclusive, considera-se que esse caminho produz diferentes perspectivas científicas e pedagógicas, e, até mesmo, novos rumos aos currículos e nos princípios organizadores dos cursos de graduação em Biblioteconomia. 
A partir desse pensar, embora sem respostas precisas, indaga-se: a formação do bibliotecário mobiliza vários saberes? Que sentido se pode atribuir à prática no interior dos saberes disciplinares visando à constituição dos saberes experienciais e profissionais?

Enfim, no iceberg da formação superior e, de modo pontual, na Biblioteconomia, há várias questões que podem convergir com a teoria e a prática, e que, certamente, podem (re)organizar e transformar práticas pedagógicas amparadas pela reflexão e ação.

\section{A PERSPECTIVA CURRICULAR E OS ASPECTOS TEÓRICO-PRÁTICOS}

Neste diálogo é importante observar as múltiplas variáveis que envolvem a materialização do ensino e a produção de saberes. Dentre estas, destacam-se concepções de currículo e suas implicações no fazer pedagógico dos decentes.

É importante o olhar conceitual sobre currículo, o qual Apple (1994, p.59) postula:

O currículo nunca é apenas um conjunto neutro de conhecimentos [...]. Ele é sempre parte de uma tradição seletiva, resultado da seleção de alguém, da visão de algum grupo acerca do que seja conhecimento legítimo. É produto de tensões, conflitos e concessões culturais, políticas e econômicas que organizam e desorganizam um povo.

Somada à ideia de Saviani (2008, p. 16), "[...] currículo é o conjunto das atividades nucleares desenvolvidas pela escola" e que fornece uma base de compreensão centrada na ideia de organização e desenvolvimento. Sem querer taxar de 
atividades burocráticas e estruturadas, pode-se descrever currículo como sendo o conjunto de princípios que norteia ações e revela intenções, mobiliza saberes para enfrentar os problemas e as adversidades que a realidade e o mercado apresentam.

Contudo, na produção do currículo, há uma tendência em se selecionar conhecimentos e priorizar saberes sociais, os quais, segundo Tardif (2014, p. 40), "[...] são transformados em saberes escolares (disciplinares e curriculares através das categorias, programas, matérias e disciplinas) [...]". Essa lógica do caráter descritivo de/por disciplina e de compartimentação, infelizmente, ainda se manifesta de maneira tradicional nos currículos dos cursos de biblioteconomia, sobretudo ao valorizar perspectivas estanques entre as disciplinas técnicas e de cunho humanista-social.

Essa impressão leva ao pensamento de condicionantes favoráveis à reflexão e ação. É preciso pensar na existência de um currículo que, por um lado, estabeleça teorias de ensino que possibilitem transmutar ideários tradicionais para ideários necessários, e, por outro, abarque a modernidade do fazer, sem necessariamente atender exclusivamente aos ditames do capital. Deve-se proporcionar vínculos durante a formação com a vivência, com a experiência e a teoria, tornando esse profissional um intérprete da realidade. Acredita-seque isso favoreça a orientação do pensar e agir, formulando reflexões sobre os espaços e mercados informacionais na sociedade, e resultando na reverberação da emancipação profissional. 
É expressivo o valor do currículo nos processos formativos. Por isso, Tardif (2014, p. 35) alerta para as armadilhas, que facilmente se colocam no cotidiano docente, a exemplo do que enfatiza:

Os educadores e os pesquisadores, o corpo docente e a comunidade cientifica tornam-se dois grupos cada vez mais distintos, destinados a tarefas especializadas de transmissão e de produção dos saberes sem nenhuma relação entre si. Ora, é exatamente tal fenômeno que parece caracterizar a evolução atual das instituições universitárias, que caminham em direção a uma crescente separação das missões de pesquisa e de ensino, [extensão].

Essa armadilha é visível. Na prática, por alguma razão, tem sido comum privilegiar ou explorar, de maneira aleatória, os aspectos teóricos ou teórico-práticos de determinados componentes curriculares, esquecendo-se, muitas vezes, de distinguir o essencial do secundário, o clássico do efêmero (GAMA; DUARTE, 2017; SAVIANNI, 2008).

Trazendo essa discussão para a realidade didáticopedagógica dos cursos de Biblioteconomia, cabe aos seus docentes analisar na unidade de conteúdo e forma se a dinâmica do currículo é adequada e compatível para formar os bibliotecários que a sociedade necessita e que possam enfrentar e superar os desafios atuais. Para tanto, essa análise deve ser efetuada em conjunto com outras condições que se configuraram nos projetos pedagógicos dos cursos, os quais, comumente, perduram ao longo de décadas.

Nesse sentido, acredita-se que, para as análises e determinações curriculares não bastam a avaliação de conteúdos ou de metodologia das aulas, mas é necessário um 
aprofundamento do estudo sobre as condições reais implícitas, explícitas, formais e informais, como considera Giroux (1986, p. 69). Ao mesmo tempo, não se pode perder de vista as diretrizes curriculares nacionais dos cursos de graduação em Biblioteconomia, posto que são:

[...] uma referência para as IES definirem seus currículos plenos, em termos de conteúdos básicos e conteúdos profissionais essenciais para o desenvolvimento de competências e habilidades requeridas para os egressos da área/curso. A presença de conteúdos essenciais garante uma uniformidade básica para os cursos oferecidos (PRUDÊNCIO; RODRIGUES, 2015, p. 3).

Sendo assim, desde a implantação, em 2001, das Diretrizes Curriculares Nacionais para os cursos de graduação em Biblioteconomia, materializadas no Parecer no 492/2001, a definição do perfil profissional do bibliotecário, ainda que de maneira genérica, é a seguinte:

[...] Além de preparados para enfrentar com proficiência e criatividade os problemas de sua prática profissional, produzir e difundir conhecimentos, refletir criticamente sobre a realidade que os envolve, buscar aprimoramento contínuo e observar padrões éticos de conduta, os egressos dos referidos cursos deverão ser capazes de atuar junto a instituições e serviços que demandem intervenções de natureza e alcance variados: bibliotecas, centros de documentação ou informação, centros culturais, serviços ou redes de informação, órgãos de gestão do patrimônio cultural etc.(BRASIL, 2001, p. 32).

Com essas considerações apresentadas, deseja-se tecer reflexões e perceber $o$ sentido atribuído ao componente curricular 'Planejamento de Unidades de Informação (P.U.I.). 


\section{CONTEÚDOS DISCIPLINARES NA FORMAÇÃO ACADÊMICA DO BIBLIOTECÁRIO}

Um modelo de ensino segmentado e centrado em disciplinas tem o poder de efetivamente silenciar ou marginalizar modelos alternativos (GOODSON, 2008, p. 31).

Respondendo ao dito nessa epígrafe, existem vários aspectos igualmente importantes que respondem pela totalidade e qualidade do ensino, os quais devem ser retratados no currículo. Assim, sugestivamente ao propósito dessa discussão para os cursos de Biblioteconomia, pode-se considerar o mercado informacional e os organismos responsáveis pela organização e disseminação da informação como importante categoria de análise.

Em nível de saberes e práticas, essa discussão pode ser traduzida através da valorização dos estudos de Gestão da Informação em Organizações, de modo a estabelecer como ponto de partida as competências significativas de gestão, as quais são necessárias ao exercício profissional em contexto organizacional, composto por relações sistêmicas complexas, incertas e descontínuas.

Certamente, com esses aspectos, se o desejo for produzir efeitos significantes na aprendizagem,será fundamental possibilitar transposições entre os cenários de mercado e ambiente de negócio se as bases socioculturais.Portanto, há de se introduzir, além das dimensões intra-organizacionais, das práticas organizacionais e técnico-operativas em bibliotecas e unidades de informação de um modo geral.Urge estabelecer um 
diálogo profícuo que envolva temas como sistemas socioeconômicos, políticas de informação e educação, direito à informação e democracia na sociedade informacional, contribuindo para uma formação omnilateral do profissional.

Convém salientar que os exemplos supracitados são apenas uma pequena amostra de situações nas quais o componente curricular de Geografia pode auxiliar no sentido de propiciar uma intervenção pedagógica pautada na transversalidade. As realidades de cada escola são diferentes, e os momentos e as condições oportunas para encaminhar um trabalho dessa natureza variam em função das características inerentes a cada ambiente de aprendizagem.

Em suma, os exemplos em destaque são apenas amostras de temas, os quais são considerados para o funcionamento de unidades de informação, posto que a realidade de cada sistema de informação é diferente e possui condições estruturais diversificadas.Torna-se fundante produzir valores e regras a partir da produção de saberes e conhecimentos técnicocientíficos, já que tais práticas não podem ser dispensadas, congeladas e realizadas linearmente, pois são exercidas na interação de sujeitos e nas intencionalidades de realidades concretas.

Sobre isso, é importante atentar para a reflexão de Angelin (2010, p. 6):

[...] as profissões modernas [biblioteconomia] têm como característica a prestação de serviço para toda a coletividade, atendendo qualitativamente as suas necessidades. E que o retorno desta prestação não está mais alicerçado apenas no ganho econômico, 
tradicionalmente conhecido como remuneração, mas sim, no reconhecimento coletivo da importância da função desempenhada.

Nota-se que esses entrelaçamentos entre as várias perspectivas vão ao encontro da concepção de currículo integrado e ao que estabelece as Diretrizes Curriculares Nacionais (D.C.N), quando elege as competências e habilidades dos graduados em Biblioteconomia. Dentre estas, pode-se destacar as seguintes:

[...]gerar produtos a partir dos conhecimentos adquiridos e divulgá-los;formular e executar políticas institucionais; elaborar, coordenar, executar e avaliar planos, programas e projetos; utilizar racionalmente os recursos disponíveis; desenvolver e utilizar novas tecnologias; traduzir as necessidades de indivíduos, grupos e comunidades nas respectivas áreas de atuação; desenvolver atividades profissionais autônomas, de modo a orientar, dirigir, assessorar, prestar consultoria, realizar perícias e emitir laudos técnicos e pareceres; responder a demandas sociais de informação produzidas pelas transformações tecnológicas que caracterizam o mundo contemporâneo (BRASIL, 2001, p. 32).

Nessa perspectiva, observa-se que, para promover as competências e habilidades explicitadas no âmbito do documento oficial que referencia a D.C.N/Biblioteconomia e a existente relação dialética do mundo informacional, o curso de Biblioteconomia da UFMA, com base nas dimensões técnicooperativas, ético-políticas e teórico-metodológicas, estabeleceu em seu Projeto Pedagógico (UFMA, 2006) em vigor desde 2010 (atualmente em estudo de atualização, previsto para vigorar no segundo semestre do ano 2020), a matriz curricular sustentada por três eixos e seus respectivos núcleos: 
a) Eixo I - Biblioteconomia e Ciências Interdisciplinares;

b) Eixo II - Construção das Práticas Profissionais;

c) Eixo III - Construção da prática de pesquisa e atividades profissionais.

Destarte, o eixo II e seus dois núcleos são referências para os fundamentos do trabalho profissional em diferentes sistemas de informação, cuja proposição de centralidade se pauta em Processamento e Tecnologia da Informação e Gestão e Organização dos Serviços e Produtos Informacionais.

Tomando como ponto de análise neste texto o núcleo que trata da gestão e organização dos serviços e produtos informacionais, identifica-se no seu conjunto treze componentes curriculares, os quais abrangem: Teorias de Administração; Psicologia Organizacional e do trabalho; Organização de unidades de informação; Estudo de usuários de informação; Fontes de informação; Planejamento em unidades de informação; Política Editorial; Referência; Marketing em unidades de informação; Arquivística; Formação e desenvolvimento de coleções;Gestão de bibliotecas especializadas e universitárias; Gestão de bibliotecas públicas e escolares.

É perceptível que esse grupo de disciplinas é a sustentação da ação profissional vinculada ao processo de gestão e organização dos produtos, recursos e serviços informacionais em quaisquer formas. Esse grupo busca capacitar o futuro profissional para a elaboração e execução de 
políticas e práticas administrativas, aplicação empreendedora e qualidade em unidades de informação.

Ressaltam-se as contribuições interdisciplinares e colaborativas, as quais dão uma concepção de currículo integrado, tendo em vista que a Biblioteconomia enquanto ciência procura explicitar na sua formação científica uma relação de dialogicidade com os demais ramos do conhecimento. Caso contrário, essa área do conhecimento se refugiaria num isolacionismo que a remeteria numa inelutável condição de saber inútil e descompromissado com a formação do profissional da informação em sua plenitude.

$\mathrm{Na}$ intencionalidade desse conjunto de elementos disciplinares, fatalmente o uso dos saberes pelos sujeitos formadores implicaria, portanto, pensar uma formação bibliotecária hábil para gerir, ocupar cargos e funções de gerência, além de desenvolver projetos de consultoria no mercado de produção informacional, como bibliotecas e sistemas de informação. Por fim, o discente se sentiria competente para empreender negócios e decisões estratégicas.

Para construir essa compreensão, todavia, é fundante considerar além do corpo teórico próprio, o caráter interdisciplinar da Ciência Biblioteconômica, que busca em outras ciências referenciais e princípios para os contextos de sua aplicação. Aqui, como exemplo, citam-se as Ciências da Administração, que possibilitam conhecer sobre Mercado e Marketing; Planejamento Estratégico; Responsabilidade Social e 
Terceiro Setor; Serviços e Teoria da Administração e das organizações.

Com esse realce, evidencia-se a contribuição do trabalho docente no decorrer da oferta do componente curricular Planejamento em unidades de informação, objetivando alcançar metas estabelecidas, ou resultados previamente determinados, no Projeto Pedagógico e, por conseguinte, no plano de trabalho desse componente curricular.

\section{A SOCIALIZAÇÃO DE UMA EXPERIÊNCIA DOCENTE}

Esta seção apresenta um relato de experiência vivenciada durante o desenvolvimento do componente Planejamento em unidade de informação, do curso de Biblioteconomia da Universidade Federal do Maranhão. Busca-se contribuir para uma reflexão mais ampla sobre o alcance desses saberes e para a lógica da competência técnico-social do mercado, assim como para a metodologia atualmente em uso nesse componente.

O componente Planejamento em unidades de informação no curso de Biblioteconomia da UFMA é previsto para o quinto período e possui $60 \mathrm{~h}$ horas de atividades distribuídas entre teoria e prática, sendo respectivamente designadas $40 \mathrm{~h}$ e $20 \mathrm{~h}$ de atividades para atender à seguinte ementa: Processo de Planejamento em unidades de informação; Histórico, Princípios e Filosofia do Planejamento; Planejamento como instrumento de gestão de unidades de informação; Tipos, modelos, técnicas e instrumentos de planejamento; Cenários e Indicadores para o 
planejamento estratégico; Planejamento de serviços e produtos de informação; Planos, Programas e Projetos para unidades de informação.

O componente apresenta uma estrutura disciplinar vinculada ao núcleo profissionalizante, que, no decorrer de sua execução, tem explorado teorias que mobilizam saberes de outros campos, tais como Psicologia Organizacional, Metodologia da Pesquisa, Administração, Estatística, Tecnologia, Políticas Públicas. No segmento da prática, através da pesquisa diagnóstica, cabe conhecer a realidade empírica e apropriar-se dos problemas relacionados à gestão e funcionamento das unidades informacionais, bem como à compreensão da cultura organizacional e à operacionalização das estruturas institucionais para as atividades de informação.

Desse modo, constata-se o crescimento do número de unidades de informação nesta capital, que tem variado sobre tipos e naturezas e processos informacionais, desde os tradicionais aos mais inovadores, levando os alunos a valorizarem outros saberes como aqueles da experiência social e cultural, do senso comum e da prática no campo da Biblioteconomia.Tais reflexões produzem conhecimento e descobertas para apresentarem soluções viáveis para as realidades pesquisadas.

Pontualmente, observando da perspectiva docente, 0 professor é desafiado a estabelecer o que Chevallard (1991) denomina de processos transpositivos-didáticos, ou seja, apresentar procedimentos pedagógicos e estratégias de 
aprendizagem que valorizem a troca de saberes e a gestão de conteúdos, articulando de maneira integrada teoria e prática. Esses processos mobilizam conhecimentos transdisciplinares para o processo de ensino-aprendizagem. A partir desse caminhar, tem-se a certeza de que se pode controlara fragmentação entre teoria e prática, superando o critério da sequência disciplinar.

Sobre superar essa questão, autores como Gauthier (2004), Goodson (2008) e Freire (1985) apontam a pesquisa como um aporte teórico e metodológico da ação pedagógica, a qual se posta como um veículo integrador do currículo. Em complemento, de modo bastante esclarecedor, Gesser e Ranghetti (2011) colocam pontualmente: "Isto requer que se faça uso de projetos, problematizações, metodologias ativas, solução de problemas, entre outros, na medida em que são os vetores da integração curricular e da prática docente interdisciplinar" que, pelo exercício da disciplina, se constituem em práticas edificadas no curso de Biblioteconomia da UFMA.

Nessa direção, almeja-se para o curso de Biblioteconomia um projeto de formação profissional que assegure uma aprendizagem significativa, visando ao estabelecimento de competências e habilidades, as quais são necessárias ao bom desempenho da prática profissional, técnica e social, e ao amplo mercado de informação. Aqui, o termo aprendizagem significativa corresponde a uma categoria trabalhada pelo teórico David Ausubel, e explorada por Moreira (2010, p. 1) é "[...] um processo por meio do qual uma nova informação 
relaciona-se, de maneira substantiva (não-literal) e nãoarbitrária, a um aspecto relevante da estrutura de conhecimento do indivíduo". Ou seja, o conhecimento só é possível quando são articulados os novos conhecimentos que se adquirem com o conhecimento prévio que o aluno possui. Assim, foge-se da técnica descontextualizada, já que:

Existe uma demanda por um profissional possuidor de uma visão holística, polivalente ou multiespecializada pois, para o momento, não basta que esse profissional seja especializado em técnicas de transferência ou organização da informação: é preciso ser um estrategista e entender como funciona um mundo competitivo e globalizado, em constante transformação (BAPTISTA; MUELLER, 2005, p. 37).

Em referência ao modelo profissional do bibliotecário, entre as décadas de 1980 e 1990, no Brasil, novos conceitos e perfis foram colocados em discussão pelos estudos do professor José Augusto Guimarães (1997). Essas discussões se referiam ao Moderno Profissional da Informação - MIP, que, dentre as várias linhas de ação, destaca:

Gerência de unidades (e sistemas) de informação, onde o MIP, em um contexto administrativo, está diretamente envolvido com o "ambiente informativo", o "staff informativo" e os recursos informativos, dandoIhes "coesão e coerência. Para tanto, interfaces com a Administração, a Economia e a Psicologia emergem como necessárias à atuação do profissional.Se antes a visão do bibliotecário, [...] era de um técnico em seu sentido estrito, hoje se impõe a visão do "manager", racionalizando procedimentos (e gastos), indo em busca de (e compartilhando) recursos, estabelecendo parcerias e integrando sua unidade de informação a sistemas mais amplos.

Essa ideia de Guimarães (1997) se coaduna com as proposições estabelecidas pelas D.C.N e pelo Projeto 
Pedagógico de Biblioteconomia em vigência na UFMA, embora esses documentos datem há mais de uma década. Ao mesmo tempo, eles demonstram o quão atual são as suas propostas, pois ajudam a perceber as dimensões e saberes necessários para atender ao conjunto de fatores constituintes da atmosfera da formação profissional a ser desenvolvida pelas Instituições de Ensino Superior (IES).

Ademais, o domínio sobre o mercado de informação é decisivo para o processo de criação de um ambiente de ensinoaprendizagem. A partir disso, exploram-se a criatividade e o diálogo entre os indivíduos para desenvolver a proatividade, a flexibilidade, a cultura do trabalho e a mobilização dos valores multidisciplinaridades, ou seja, as competências para compreensão do processo produtivo tão necessários à tomada de decisões.

Evidencia-se, ainda que empiricamente, a importância e a incorporação dos conteúdos formativos produzidos no contexto do mundo trabalho para suprir as novas competências e os perfis profissionais. Por isso, é altamente positiva a inserção desses conteúdos na experiência de sala de aula com P.U.I. Desse modo, alcança-se plenamente o objetivo desse componente, que é possibilitar ao discente do curso de Biblioteconomia a apreensão e a construção de conhecimentos teóricos e práticos no processo de planejamento de sistemas e unidades de informação. Além disso, esse componente favorece a compreensão dos elementos essenciais da gestão estratégica de acordo com as diversas realidades organizacionais. 
No rol dos componentes curriculares, P. U. I é um daqueles componentes que contribui de modo incisivo para contextualização e gestão da organização em relação ao mercado produtivo, permitindo a compreensão das relações de poder institucionalizadas e das dimensões ético-políticas que permeiam todo o gerenciamento em bibliotecas e sistemas de informação. Em tempo, requer uma visão interna e externa da organização para que desenvolva seu trabalho nos níveis estratégico, tático e operacional, como também nos processos micro e macro de gestão da informação.O foco é transformar a visão em resultados operacionais e otimização dos recursos físicos, humanos e financeiros em prol do pleno funcionamento do sistema informacional em qualquer ambiente.

Com efeito, alia-se às ferramentas de administração e gestão para evitar duplicidade de esforços, respaldar as tomadas de decisão e fomentar o processo de produção até a distribuição do produto e satisfação dos usuários ou clientes. Partindo desse pressuposto, existe uma ferramenta primordial que toda organização, seja ela pública ou privada, ou de qualquer segmento de atuação do mercado, necessita utilizar. Essa ferramenta é conhecida como Planejamento Estratégico (PE).

Sem dúvidas, esse componente é apontado como de expressiva importância na formação de profissionais da área da Biblioteconomia, pois o planejamento é inerente à ação humana, tornando-se imprescindível ao desenvolvimento das forças produtivas de informação e definindo divisas nos espaços 
públicos e nos direitos informacionais. Enfim, a vida humana, entre riscos, sucesso e sobrevivência, é permeada por ações planejadas.

Outro aspecto que é bastante importante e que se beneficia sobremaneira dos conhecimentos teóricos desse componente é a seleção de soluções para um determinado problema. Por isso, cabe ao bibliotecário a escolha daquele produto/serviço/ação que atenda tanto aos requisitos técnicos estabelecidos quanto à disponibilidade de recursos para solucionar e colocar em prática. Dentre os aspectos tipicamente desenvolvidos para possibilitar essa tomada de decisão estão os tópicos da última unidade, que é o desenho de planos de ação e elaboração de programas e projetos, os quais possibilitam exercitar os conhecimentos adquiridos sob o domínio de uma realidade concreta e sob a visão dos problemas cotidianos em unidades de informação.

A importância e a extensão dos conteúdos associados a esse componente exigem do docente responsável pela condução do processo um meticuloso planejamento didático para a realização dos encontros em sala de aula, bem como dos recursos extra sala, a fim de facilitar o processo de ensinoaprendizagem.

Outro avanço na proposta didático-pedagógica desenvolvida tem sido a possibilidade de um trabalho conjunto com professores de diferentes componentes para o exercício de práticas que envolvam um grupo de discentes matriculados também em outros componentes. Esse foi o caso de Política 
Editorial, quando foi solicitada a definição da identidade institucional da Revista Bibliomar ${ }^{2}$. Na verdade, essa integração mostra que o planejamento vem a ser um reduto de várias especialidades, agregando disciplinas que terminavam por fragmentar a formação do aluno.

Registra-se que as discussões teóricas são elaboradas a partir de uma bibliografia básica e socializadas em seminários temáticos e apresentação de um ensaio que verse sobre a relação planejamento e bibliotecas. Enquanto a aplicação da prática desses conteúdos apresentados ocorre por meio de exercícios e/ou de casos em situação real em unidades de informação de diversas naturezas, há uma estreita relação com a oferta de mercado de bibliotecas na cidade, como ilustra o exemplo descrito anteriormente.

Dado o número superior a vinte discentes inscritos no componente, tem-se trabalhado com a escolha simultânea das diversas unidades de informação para exercitar os conhecimentos e elaborar estudos de caso.

De modo geral, adota-seno conjunto das metodologias ativas para o ensino e aprendizagem várias estratégias, como aulas expositivas e dialogadas, levantamento bibliográfico/documental, leitura e discussão de textos, estudo em grupo (formação de grupos), pesquisa empírica e experimental, seminários, estudo de caso (case), visitas orientadas, produção textual.

2 Periódico laboratório do curso de Biblioteconomia/UFMA, sob a responsabilidade dos discentes matriculados no componente curricular Política Editorial. 
O processo de aprendizagem é indutivo, posto que os participantes são motivados a desenvolver regras e procedimentos para a elaboração de todas as etapas do processo de planejamento em determinada unidade de informação, desde a escolha do campo de estudo, elaboração do diagnóstico situacional, até o desenvolvimento de soluções para problemas específicos ementados no plano de ação,utilizando, em geral, os seguintes procedimentos: mapear e selecionar unidades de informação; identificar o modelo gerencial e de funcionamento da organização; confrontar a descrição com o referencial teórico; levantar controvérsias que apontem diferentes interpretações, de modo a elaborar um diagnóstico; levantar e manipular dados quantitativos e qualitativos apropriados para a compreensão da realidade (utilização de documentos institucionais, fontes primárias, via entrevista e observação); elaboração de planos.

Em seguida, há o julgamento de problemas e indicação de soluções em ordem de prioridade, com definição de ações para curto, médio e longo prazos e a construção de projetos para um processo de intervenção.Como etapa conclusiva, há a elaboração de relatórios,a socialização dos planos institucionais, os quais são esmiuçados em narrativas de situações-problema, e a exposição da contribuição do estudo para a organização selecionada. Vale informar que, em cada etapa cumprida, os grupos apresentam suas produções.

Por fim, as estratégias de aprendizagem e avaliação do processo previstas no programa da disciplina são acordadas 
com o grupo. Nesse item prioriza-se a observação da participação e o desempenho individual no decorrer das aulas teóricas e práticas, verificação da capacidade e domínio no desenvolvimento da pesquisa de campo, e a elaboração de documentos técnicos (diagnóstico, relatório, plano e projetos) orientados pelo planejamento estratégico da organização.

\section{CONSIDERAÇÕES FINAIS}

A discussão sobre o papel dos cursos de graduação na formação do capital bibliotecal, apesar de não ser nova, ainda possui lacunas na aproximação entre o sistema de ensino e o mercado. Ademais, identifica-se que muitas bibliotecas e serviços de informação não elaboram e executam seus planos estratégicos ou, quando o executam, acontece de forma equivocada. Para isso há duas explicações.

A primeira, empiricamente, tem-se verificado que os bibliotecários recém-formados enfrentam o mercado de trabalho com insegurança e alguns são incapazes de uma inserção competitiva nas funções típicas de gestores de bibliotecas. A segunda é descrita pelos estudos de Almeida (2005), Silva (2017), Marinho e Silva(2018), que tratam sobre a falta de tempo para planejar e/ou o fato dos bibliotecários não reconhecerem a finalidade do planejamento, deixando de considerar que o tempo dispendido seja importante para o futuro da instituição.

Para corrigir essas posturas é importante pensar em formas de flexibilizar o sistema de ensino, a exemplo de residências 
pedagógicas ou programas de imersão para trocas de experiências, contribuindo para a elaboração de perfis adequados às exigências do mundo moderno e do futuro das incertezas.

Certamente, o ato de planejar não é uma tarefa fácil. O próprio gestor encontrará muitas barreiras as quais poderão ser eliminadas. No entanto, essas barreiras estão relacionadas, principalmente, às dificuldades com a compreensão de conceitos, estruturas e metodologias empregadas no processo de elaboração do planejamento.

Essa perspectiva requer uma reflexão dos paradigmas que suportam o estabelecimento do processo formativo e das práticas gerenciais de bibliotecários. Ou seja, é preciso prover as competências de gestão necessárias ao exercício profissional do bibliotecário em contexto de relações sistêmicas. Através dessa vivência pedagógica, tem-se a certeza que a utilização da metodologia Método do Caso - "Case" propicia a troca de aprendizagem, conhecimento e experiências entre gestores e futuros bibliotecários.

Esse conjunto de pressupostos trazidos à baila nesta oportunidade tem motivado o corpo docente e discente do curso de Biblioteconomia da UFMA a pensar pedagogicamente sobre a formação universitária do bibliotecário e os desafios do trabalho docente nas unidades curriculares,em especial no eixo 'Processo de gestão da informação e de bibliotecas', momento em que se está empreendendo a reforma curricular.

Essa discussão tem sido atual e valiosa, posto que a 
Biblioteconomia, de modo positivo, tem se colocado à frente como uma carreira e ocupação da modernidade. Pela sua importância no mercado produtivo, tem ofertado novas oportunidades profissionais e postos de trabalho.

\section{REFERÊNCIAS}

ALMEIDA, Maria Cristina Barbosa. Planejamento de bibliotecas e serviços de informação. Brasília: Briquet de Lemos, 2005.

ANGELIN, Paulo Eduardo. Profissionalismo e profissão: teorias sociológicas e o processo de profissionalização no Brasil. REDD - Revista Espaço de Diálogo e Desconexão, Araraquara, $v$. 3, n. 1, jul./dez. 2010.

APPLE, Michael W. Ideologia e Currículo. São Paulo: Brasiliense, 1994.

BAPTISTA, Sofia Galvão; MUELLER, Suzana Pinheiro Machado. Considerações sobre o mercado de trabalho do bibliotecário. Información, Cultura y Sociedad, n. 12, p. 35-50, 2005.

BRASIL.PARECER CNE/CES 492/2001. Despacho do Ministro em 4/7/2001. Diário Oficial da União, Seção 1e, p. 50, 9 jul. 2001.

CHEVALLARD, Yves. La tranposición didáctica: Del saber sabio al saber enseñado. Traduzida por Claudia Gilman. Buenos Aires: Editora Aique, 1991.

GAMA, Carolina; DUARTE, Nozella Newton. Concepción de currículo en Dermeval Saviani y sus relaciones con la categoría marxista de libertad. Interface, Botucatu, v. 21, n. 62, p. 521530, 2017.

GESSER, Veronica; RANGHETTI, Diva Spezia. O Currículo no ensino superior: princípios epistemológicos para um design contemporâneo diretrizes curriculares nacionais e a construção de propostas curriculares inovadoras: Revista e-curriculum, São Paulo, v. 7, n. 2, ago. 2011. Disponível em: 
http://revistas.pucsp.br/index.php/curriculum Acesso em: 17 dez. 2019.

GOODSON, Ivor. As políticas de currículo e de escolarização. Petrópolis: Vozes, 2008.

GIROUX, Henry. Teoria Crítica e Resistência em Educação. Para além das teorias de reprodução. Tradução de Ângela Maria B. Biaggio. Petrópolis: Vozes, 1986

GUIMARÃES, Jose Augusto Chaves. Moderno Profissional da Informação elementos para sua formação no Brasil.

Transinformação, v. 9, n. 1, p. 124-137, jan./abr. 1997

LEVY, Paolo Mansur. Educação e crescimento: uma resenha da literatura. In: TAFNER, Paulo et al. Caminhos trilhados e desafios da educação superior no Brasil. Rio de Janeiro: EdUERJ, 2016.

LOJKINE, Jean. A Revolução informacional. São Paulo: Cortez, 1995.

MARINHO, Raimunda Ramos; SILVA, Marcio. PLANEJAMENTO ESTRATÉGICO EM BIBBLIOTECA UNIVERSITÁRIA - Análise da percepção de gestores e técnicos bibliotecários. SNBU, 2018.

MARTINELI, Telma Adriana Pacifico. Implicações do neoliberalismo e da teoria do capital humano na política educacional brasileira: a década de 1990 em questão. In: CONGRESSO NACIONAL DE EDUCAÇÃO DA PUCPR (EDUCERE), ENCONTRO SUL BRASILEIRO DE PSICOPEDAGOGIA, 9., 2009. Anais [...]. Curitiba: PUCPR, 2009.

MOREIRA, M.A. O QUE É AFINAL APRENDIZAGEM

SIGNIFICATIVA? (After all, what is meaningful learning?), 2010. Disponível em:

http://moreira.if.ufrgs.br/oqueeafinal.pdf. Acesso em: $17 \mathrm{dez}$. 2019.

PRUDENCIO, Dayanne da Silva; RODRIGUES, Mara Eliane Fonseca. Diretrizes curriculares nacionais e a construção de propostas curriculares inovadoras: um estudo de cotejamento dos projetos pedagógicos de curso (ppc). In: ENCONTRO 
NACIONAL DE PESQUISA EM CIÊNCIA DA INFORMAÇÃO, 16., 2015, Salvador. Anais[...]. Salvador: ANCIB, 2015.

POCHMANN, M. A década dos mitos: o novo modelo econômico e a crise do trabalho no Brasil. São Paulo: Contexto, 2001.

SAVIANI, Demerval. Pedagogia histórico-crítica: primeiras aproximações. 10a ed. Campinas: Autores Associados; 2008.

SILVA, Márcio André Pereira da. Perspectiva dos Bibliotecários acerca da elaboração do Planejamento Estratégico no Núcleo Integrado de Bibliotecas da Universidade Federal do Maranhão - NIB/UFMA. 2017. 88f. Trabalho de conclusão de Curso (Biblioteconomia) - Centro de Ciências Sociais, Universidade Federal do Maranhão, São Luís, 2017.

TARDIF, Maurice. Saberes docentes e formação profissional. Petrópolis, RJ: vozes, 2014.

UFMA. Projeto Político Pedagógico do Curso de Biblioteconomia. São Luís: UFMA, 2006. 